\title{
Bank regulation and supervision and its welfare implications is
}

\author{
Mustafa Kilinc $^{\text {a,1 }}$, Bilin Neyapti ${ }^{\text {b,* }}$ \\ ${ }^{a}$ Central Bank of the Republic of Turkey, Research and Monetary Policy Department, Istiklal Cad 10 Ulus, 06100 Ankara, Turkey \\ b Bilkent University, Ankara, Turkey
}

\section{A R T I C L E I N F O}

\section{Article history:}

Accepted 31 August 2011

\author{
JEL classification: \\ E44 \\ G28 \\ 016
}

Keywords:

Bank regulation and supervision

Growth

\begin{abstract}
A B S T R A C T
This study provides a general equilibrium model to explore the welfare implications of bank regulation and supervision (RS). The model supports the basic expectations regarding the positive effects of RS on the growth rate, output, credit, investment, wages and profits; and its negative effects on the interest rate. In addition, RS is observed to lead to a convergence effect. Furthermore, it is observed that the decision of banks to monitor and charge differentiated interest rates to firms depends on the distribution of firm-specific moral hazard rates; bank monitoring increases profits as the distribution of producer type improves.
\end{abstract}

(c) 2011 Elsevier B.V. All rights reserved.

\section{Introduction}

The positive linkage between economic growth and financial market development has been well established. Dating back to Schumpeter (1911), the literature emphasizes the transaction cost reducing role of financial intermediaries that facilitate investment and hence lead to growth (see, for example, Goldsmith, 1969; McKinnon, 1973; Shaw, 1973; Romer, 1986, 1990; Lucas, 1988; Rebelo, 1991). The interaction between finance and growth has also been examined using an endogenous growth modeling framework (see, for example, Greenwood and Jovanovic, 1990; Bencivenga and Smith, 1991). In addition, there is compelling evidence regarding the positive effect of financial sector development on economic growth (see, for example, King and Levine, 1993; Levine, 1997, 2003; Beck et al., 2000). ${ }^{2}$

Given that banking systems are, to a large extent, still characterized by traditional functions, this paper focuses on a crucial institution: bank regulation and supervision (RS) that aims to increase banks' effectiveness in serving these functions via reducing the

\footnotetext{
is We thank Cagri Saglam and an anonymous referee for their valuable comments.

* Corresponding author. Tel.: +90 312290 2030; fax: +90 3122665140.

E-mail addresses: Mustafa.kilinc@tcmb.gov.tra (M. Kilinc), neyapti@bilkent.edu.tr (B. Neyapti).

1 Tel.: +90 3125075409 .

2 Moreover, Levine (1998) argues that legal rights of creditors contribute to bank development.
}

adverse selection and moral hazard problems. ${ }^{3}$ We propose an original formal model to analyze the implications of RS, whose importance has been heightened with a series of recent financial crises that have had global impact. ${ }^{4}$ A large number of recent academic studies, as well as the reports of the Bank for International Settlement, have extensively discussed the elements that contribute to banking systems' prudence; the revised Basle standards emphasize those elements in providing guidance for banking sector reforms around the world. ${ }^{5}$

Taking stock of the arguments provided in this literature, Neyapti and Dinçer (2005) propose a comprehensive set of criteria to measure the intensity of legal framework for RS, based on the aspects of restrictiveness, transparency, and the width of coverage of banking laws. ${ }^{6}$ The list of 98 criteria focuses on the extent of transaction cost reduction in the banking sector and covers legal provisions ranging from bank capital requirements, management, reporting, ownership,

\footnotetext{
${ }^{3}$ Universal banking is argued to help the banking sector benefit from economies of scale and risk diversification. Barth et al. (2004) argue that regulations on securities, insurance, real estate activities, which are features of universal banking, do not contribute to financial market development but increase financial instability. Drawing upon the lessons drawn from the 2007 global crises, this paper, which specifically focus on the traditional banking functions, argues to the contrary.

${ }^{4}$ Namely, the East Asia crisis in 1997, Argentine crisis in 2001, and especially the US mortgage-based securities crisis in 2007, the last of which also drew attention to the importance of universal banking regulation.

${ }^{5}$ Last crisis has brought macroprudentials to the fore, hence drawn attention to the importance of universal banking regulation and led to the formation of institutions such as European Systemic Risk Board and European System of Financial Supervisors.

${ }^{6}$ The indices are based on 98 criteria that cover legal provisions such as bank capital requirements, management, reporting, ownership, lending, supervision and deposit insurance.
} 
lending, supervision to deposit insurance. Using the resulting index, the authors provide empirical evidence on the positive relationship between RS and growth in the sample of transition economies. The index of RS also exhibits a positive association with deposits and investment, and a negative association with non-performing loans as well as output losses arising from crises. ${ }^{7}$

This paper provides an original model that focuses on the welfare implications of bank regulation and supervision in a dynamic general equilibrium framework. The existing literature has addressed various related issues only in partial equilibrium frameworks: Holmstrom and Tirole (1997) investigate the optimal monitoring intensity based on the interactions between intermediaries' and firms' net worth. Stiglitz and Weiss (1981) and Myers and Majluf (1984) present models where adverse selection under imperfect information regarding the project returns of the borrowers leads to external finance premium. Jensen and Meckling (1976) present a model with moral hazard under costly monitoring and incentive problems and show that lenders require a premium for the compensation of moral hazard. Focusing solely on capital requirements, Rochet (2004) provided a study of endogenous bank regulation in conjunction with monetary policy. Repullo and Suarez (1999) study the effects of monetary policy on entrepreneurial moral hazard. Absent internal financing, the current model differs from the existing literature in that firms are not distinguished on the basis of the moral hazard rates that are linked with their net worth; it also refrains from monetary policy issues.

The current model is based on the optimal solution of a dynamic general equilibrium model of an economy that is composed of consumers, firms and banks, which may be perfectly competitive or monopolistic. In order to focus on the linkage between the real sector and RS, we avoid the issue of heterogeneity in risk exposure by assuming a representative bank. A representative consumer either owns a representative firm, or, alternatively, firms that are distinguished on the basis of individual moral hazard rates. RS affects (positively) the rate at which a firm transforms credit into investment (in accord with the transaction costs that arise from interrupted production in the Diamond-Dybvig model), and the rate at which credit is paid back to the banks. When firms are assumed to be homogenous, banks are exposed only to a systemic risk imposed by RS. For the sake of simplicity, it is assumed that the only type of moral hazard is that of producer's. ${ }^{8}$ RS also affects consumers' trust in the banking sector and hence the deposit share of savings (both positively). ${ }^{9}$

Simulations of the model solution support that RS positively affects the transitory growth rate as well as the steady-state income level, wage rate and capital accumulation. ${ }^{10}$ As expected, the model also implies that the interest rate decreases in RS and in the quality of producers. Accordingly, simulations reveal that the optimal choice of a social planner, or a bank owner, would result in the highest possible value of RS. ${ }^{11}$ The particularly interesting implications of the model are observed in the case of heterogeneous producers and the banks facing the question of monitoring or no-monitoring. The model

\footnotetext{
${ }^{7}$ See Dincer and Neyapti (2010) for the former; the latter evidence is available from the authors. The authors also note for example that this measure of RS does not exhibit nonlinearity in explaining the investment behaviour. Both Alen and Gale (2007) and Shehzad and de Haan (2009) also argue that regulatory intensity reduces banking crises. Based on survey-based measures of bank regulation and supervision, however, Barth et al. (2004) argue that regulatory and supervisory intensity reduces banking efficiency.

${ }^{8}$ In reality there are potential transaction costs that may emanate from banks also.

${ }^{9}$ Neyapti and Dinçer (2005) and Dincer and Neyapti (2008) argue that well designed deposit insurance schemes reinforce the quality of RS by reducing the likelihood of moral hazard in the banking system.

${ }^{10}$ Using an OLG model, Tchana (2007) obtains opposite results based on the assumption that risky investments are more productive and bank regulation limits risky, or productive, investments.

11 The bank manager may have shorter-term objectives than the owner of the bank, as in a typical principal-agent problem.
}

predicts that the adverse selection problem for banks, that is the cost of not monitoring, increases as the distribution of producers weighs heavily on the high-quality side. It is, however, optimal for banks not to monitor when the distribution of producer types weighs on the bad side (i.e. the distribution follows an F-type distribution on the quality scale). ${ }^{12}$ Above some threshold level of RS and producer types, it is also optimal for banks not to monitor.

The rest of the paper is organized as follows. Section 2 lays out the model for consumers, firms and the banks for the case of homogeneous producers. Section 3 analyzes the implications of the model for the case of heterogeneous producers, when the bank faces the options of monitoring and no-monitoring. Section 4 is devoted to the implications of the model regarding optimal RS and monitoring. Finally, Section 5 concludes.

\section{The model}

The quality of bank regulation and supervision reflects the extent to which transaction costs in the financial sector are mitigated via formal institutional mechanisms. Hence, it facilitates effective financial intermediation and thus has a positive effect on growth. ${ }^{13}$ This paper investigates the welfare effects of RS in a general equilibrium framework. The model consists of a representative consumer, a representative firm and a representative (or, alternatively, a monopolist) bank, who are all assumed to live infinitely. The depositor's trust in the banking system, ${ }^{14}$ the firm's decision to convert credit into investment as well as to repay its loan back to the bank are all positively related with RS. The model includes two main frictions in the bank intermediation process. The first one is the informational problems that lead to frictions in the deposit and credit markets, and the second one is the friction caused by the monopolistic bank.

As typical, the (representative) consumer derives utility from lifetime consumption and leisure. Its budget is composed of wage income, return on past savings, and firm's and bank's profits - since the household is also assumed to own the firm and receives dividend from the bank. Given its budget constraint, the consumer optimally chooses its consumption $(C)$ and savings $(S)$. The portion of savings that is deposited in the bank $(D)$ is positively related with RS, as RS signifies the extent of the trust in the banking system. At the beginning of each period, the consumer provides the firm with labor input $N$. The firm invests a portion of the bank credit $(C R)$, which is a positive function of RS, passing the rest on to the consumer, and returns the principal and interest on that portion of the credit back to the bank. Assuming that investment is externally financed (through bank credit), the firm optimally chooses labor and capital.

The following notations are used throughout the rest of the paper. $Y$ for output, $K$ for capital, $N$ for labor, $\Pi$ for profit, $C$ for consumption, $C R$ for credit, $D$ for deposit, $S$ for saving, $W$ for the wage bill $(w \times N)$ and $r\left(r^{D}\right)$ for the interest (deposit interest) rate. The intensity of bank regulation and supervision (RS), which is denoted by $\alpha$, can be normalized to a number between zero and one. Lower case letters are used to indicate per capita levels, such as $y=Y / N$ and $c r=C R / N$. In what follows, Section 2.1 outlines the model where banks are perfectly competitive. Section 2.2 explores the alternative case of a

\footnotetext{
12 One may consider a good distribution of firm type to result from developed informal institutions or business culture.

13 Neyapti and Dinçer (2005) provide empirical support for this argument.

14 This may be thought to be particularly captured by the deposit insurance (DI) aspect of the RS index measured by Neyapti and Dinçer (2005) and Dincer and Neyapti (2008). Deposit insurance systems may need to be more extensive in crises-prone countries than in financially healthy economies. Indeed, Dincer and Neyapti report that there is only $30 \%$ correlation between the quality of DI and the rest of the RS index; however, they also argue that their measure of DI contributes to the quality of RS. Demirguc-Kunt and Huizinga (2004), on the other hand, argue that there may be a trade-off between depositor safety and market discipline.
} 
monopolist bank that solves for the rate of interest for lending. Simulation results are also reported in each subsection.

\subsection{A perfectly competitive banking sector}

The following outlines the model set-up and solution for the representative consumer, producer and the bank, in that order. As a benchmark case, the representative bank takes interest rates as given in a perfectly competitive setting, and optimally determines the level of credit.

\subsubsection{Consumer's problem}

The representative consumer maximizes its lifetime utility from consumption and leisure $(L=1-N)$ :

$\sum_{t=0}^{\infty} \gamma^{t} U\left(C_{t}, L_{t}\right), \quad 0<\gamma<1$

subject to the following constraints

$$
\begin{aligned}
C_{t} & +S_{t} \leq w_{t} N_{t}+\alpha S_{t-1}\left(1+r_{t-1}^{D}\right)+(1-\alpha) S_{t-1}+(1-\sqrt{\alpha}) C R_{t} \\
& +\Pi_{t}^{\text {Firm }}+\Pi_{t}^{\text {Bank }}
\end{aligned}
$$

$\alpha S_{t}=D_{t}$

The consumer's budget is given in Eq. (2). Right hand side of the equation is the income of the household, consisting of six terms: the first one is the wage income from labor supplied to the firm $\left(w_{t} N_{t}\right)$. The second and third terms are the gross returns from the savings. As we explain in the text, households keep $(1-\alpha)$ part of their savings under the pillow ${ }^{15}$ and deposit remaining $\alpha$ portion in the banks. Therefore, household gets gross returns on past savings $S_{t-1}$ as follows: $(1-\alpha) S_{t-1}$ goes to the next period without any interest earnings and $\alpha S_{t-1}$ earns a gross interest rate of $\left(1+r_{t-1}^{D}\right)$. So, total income from savings $S_{t-1}$ in previous period is $\alpha S_{t-1}\left(1+r_{t-1}^{D}\right)+$ $(1-\alpha) S_{t-1}$. The fourth term, $(1-\sqrt{\alpha}) C R_{t}$, is based on the assumption that firms use $C R_{t}$ as credit from banks in period $t$, do not pay all of the credit back to banks but keep $(1-\sqrt{\alpha})$ fraction for themselves. Since firms are owned by households, we assume that they return that fraction of credit to households, $(1-\sqrt{\alpha}) C R_{t}$ is an income item for households. Last two terms are the profits of firms and banks. Since we assume that households own firms and banks in the economy, their profits are remitted to the households. Once a household gets all of his period $t$ income, it decides on how to allocate it between consumption $\left(C_{t}\right)$ or savings $\left(S_{t}\right)$, which constitutes the left hand side of the equation.

It is assumed that the non-deposited portion of savings and the non-invested portion of credits are both negatively related with $\alpha{ }^{16}$ Although separate parameters can be used to represent the extent of consumer confidence in the banking system and the extent of the (lack of) moral hazard to be committed by the producer, the use of a single term, $\alpha$, simplifies the exposition without any significant difference in the model's implications. The justification for this is as follows. As discussed earlier, the quality of bank regulation and supervision (RS) is a summary measure, guided by the index provided in Neyapti and Dinçer (2005), which is comprised of all the legal aspects of bank regulation and supervision that includes not only lending practices but also provisions related to bank management and deposit insurance. We thus conjecture that all these features complement each other in providing a measure of the banking system prudence, and hence affect the optimum behavior of all economic agents in a similar fashion.

Based on the Lagrangian method of optimization, the first order conditions of the above problem for leisure and savings yield the following expressions:

$U_{L}\left(C_{t}, L_{t}\right)=w_{t} U_{C}\left(C_{t}, L_{t}\right)$

$U_{C}\left(C_{t}, L_{t}\right)=\gamma U_{C}\left(C_{t+1}, L_{t+1}\right)\left[\alpha\left(1+r_{t}^{D}\right)+(1-\alpha)\right]$

where $U_{L}$ and $U_{C}$ represent the derivatives of the utility function with respect to $L$ and $C$. According to Eq. (5), the return on savings is obtained in full when $\alpha=1$. However, the consumer gets less than full return on his or her savings, because savings are only partially deposited (when $\alpha<1$ ). In the steady state, when $\alpha<1$, there will be a premium in the deposit rate above the interest rate implied by $\gamma$ : $\left(1+r^{D}\right)=[(1 / \gamma)-(1-\alpha)](1 / \alpha)>(1 / \gamma)$. This premium and the deposit rate decrease in $\alpha$ and the premium disappears when $\alpha=1$. Therefore, when there is a lack of confidence in the banking system, deposit rate is higher than the rate implied by $\gamma$.

\subsubsection{Producer's problem}

We assume that there is a representative producer (chosen from a continuum, facing the same technology) that maximizes its discounted stream of profits by choosing the level of $K$ and $N$ :

$\sum_{t=0}^{\infty} \gamma^{t} \lambda_{t} \Pi_{t}^{\text {Firm }}=\sum_{t=0}^{\infty} \gamma^{t} \lambda_{t}\left\{A_{t} K_{t-1}^{\beta} N_{t}^{1-\beta}-w_{t} N_{t}-\left[K_{t}-(1-\delta) K_{t-1}\right]\left(1+r_{t}\right)\right\}(6)$

where $\lambda_{t}$ is the marginal utility of the consumer and $A_{t} K_{t-1}^{\beta} N_{t}^{1-\beta}$ is a Cobb-Douglass type production function, where $A$ denotes the level of technology, which we assumed to be equal to 1 without loss of generality. Producer pays wage $(w)$ for each unit of labor it hires $(N)$ and interest for the credit used for investment, which is externally financed entirely through bank credit $(C R)$. Capital stock evolves according to the process:

$K_{t}=(1-\delta) K_{t-1}+I_{t}$

where $I_{t}$ is investment. ${ }^{17}$ The rate of conversion of credit into investment, as well as the rate of repayment of credit back to the banks, is assumed to be given by: $\sqrt{\alpha}{ }^{18}$ Hence,

$I_{t}=\sqrt{\alpha} C R_{t}$

Eq. (8) is a kind of credit-in-advance constraint for producers. Since consumers own the firms and receive their profits, the value of profit is equal to the marginal utility received from consumption. The first order conditions of the above problem for capital and labor

\footnotetext{
15 This is a simplifying assumption. In a more realistic framework, one could consider alternative investment and offshore-banking opportunities; these would probably leave the model predictions mostly unaffected, however, as long as those funds also do not return to the banking system.

16 Though deposit insurance may be an aspect of RS that directly affects the depositor behavior, other aspects of RS that help eliminate adverse-selection and moral-hazard risks may also boost the consumer's trust in the banking system-even in the absence of effective deposit insurance.
}

\footnotetext{
17 Similar expressions for investment (as a function credit) are obtained as: a game theoretic equilibrium between lenders and borrowers by Schneider and Tornel (2004); a solution to the optimal contract problem by Carlstrom and Fuerst (2001), and a solution to limited contract enforcement in Hart and Moore (1997), which all use a framework where internal financing exists.

18 The square-root formula for the investment conversion rate implies 50; $71 ; 87$ and $100 \%$ returns to credit for the RS values of $0.25 ; 0.50 ; 0.75$ and 1 , respectively. These numbers also correspond to the non-performing loan ratios for those values of RS.
} 
are:

$\left(1+r_{t}\right) U_{C}\left(C_{t}, L_{t}\right)=\gamma U_{C}\left(C_{t+1}, L_{t+1}\right)\left[\beta\left(N_{t+1} / K_{t}\right)^{1-\beta}+\left(1+r_{t+1}\right)(1-\delta)\right]$

$w_{t}=(1-\beta)\left(N_{t} / K_{t-1}\right)^{\beta}$

Eq. (9) indicates that the cost of credit in terms of foregone consumption this period is equal to next period's return on investment; investment yields the marginal product of capital plus the return (capital gain) on the non-depreciated part of the capital. Because credit demand determines the optimal level of investment, this expression implicitly accounts for the fact that the uninvested portion of the credit, which is internalized by the consumer who is also the firm owner, is also optimally determined.

\subsubsection{Bank's problem (the benchmark case)}

Taking deposits from the households and facing the market deposit and credit interest rates in a competitive setting, the representative bank maximizes its profits by optimally choosing the amount of credit in each period:

$\sum_{t=0}^{\infty} \gamma^{t} \lambda_{t} \Pi_{t}^{\text {Bank }}=\sum_{t=0}^{\infty} \gamma^{t} \lambda_{t}\left\{\left(1+r_{t}\right) \sqrt{\alpha} C R_{t}-\left(1+r_{t-1}^{D}\right) D_{t-1}\right\}$

subject to following constraint

$C R_{t} \leq D_{t-1}$

Both $C R$ and $D$ can be considered to be annual flows. Here, credit rationing is ruled out as a benchmark case of homogenous producers who face the same level of credit interest. Then, the first order condition for credit is given by Eq. (13):

$\left(1+r_{t}\right)=(1 / \sqrt{\alpha})\left(1+r_{t-1}^{D}\right)$

When there are no transaction costs $(\alpha=1)$, lending and deposit rates are equal and they are both equal to the rate of time preference. When there are transaction costs $(\alpha<1)$, however, there is an interest spread: the lending rate exceeds the deposit rate, and both rates are higher than the rate of time preference: $(1 / \gamma)<\left(1+r^{D}\right)=(1 / \alpha)[(1 / \gamma)$ $-(1-\alpha)]<(1+r)=\left(1 / \alpha^{3 / 2}\right)[(1 / \gamma)-(1-\alpha)]$. This indicates that the lending rate under no distortion $(\alpha=1)$ takes its lowest value; it increases when consumer adjusts its deposits in an inverse relation to $\alpha$; and it further increases when $\alpha$ negatively affects the producer's decision to pay credit back to the bank. ${ }^{19}$

Appendix 1 provides the list of equations that define this benchmark case of perfectly competitive bank's problem. All agents maximize their objectives with respect to the corresponding constraints. Under the perfect markets case, all prices are taken as exogenous by the agents. The list of equations in Appendix 1 and the market clearing conditions provide a full competitive equilibrium. ${ }^{20}$ Partial derivatives of the optimal interest rate, wages and credits with respect to $\alpha$ are reported in Appendix 2.

\subsubsection{Simulations}

\footnotetext{
19 Adding uncertainity and risk to the model will increase the complexity of the model considerably, altough we predict that the implications regarding $\alpha$ would remain similar to the current one.

${ }^{20}$ The model is solved and simulated using Dynare toolbox of Matlab, under the assumption of perfect foresight.
}

Fig. 1 shows the simulated trajectories of the optimal solutions of model variables. The underlying parameter values are chosen as follows: the discount factor $(\gamma)$ for a representative consumer is $0.95^{21} ; \delta=0.1$ approximates the rate of depreciation ${ }^{22} ; \beta$ (the income share of capital) assumes the value of $0.34 .{ }^{23}$ The shock to $\alpha$ is considered to be 0.1 units, leading to a jump from 0.8 to 0.9 for example. The utility of the consumer is assumed to be of a log-linear form, $U(C, N)=\log (C)+\theta \log (1-N)$, where $0<N<1$ and $\theta$ is calibrated to match the steady-state labor of $N=0.33$ that corresponds to 8 hours of daily working time.

As seen in Fig. 1, a shock to $\alpha$ causes permanent increases in capital and investment by more than $10 \%$; credit, output, deposits by about 5\%; output per capita, consumption and the wage rate by about 3\%; labor by about 1\%; and producer profits by about $4 \%$. While increases in capital, output, output per capita, consumption, and wages are gradual (spread over about 20 years); increases in credit, investment, deposit, labor and profit initially overshoot the new steady-state values, also leveling off in 20 years. In addition, it is observed that both credit and deposit interests fall gradually, the latter falling more gradually than the former, leveling off at rates $11 \%$ and below $6 \%$, down from the levels of $19 \%$ and $6.5 \%$, respectively. An interesting result is that savings fall by $7 \%$, which means that a reduction in transaction costs leads higher proportion of savings to be deposited, which results in higher credit, capital, output and consumption for the same level of savings. In other words, facing a welfare increase under higher RS, households can afford to save less.

Some variables are overshooting when going to the new steady state after an increase in $\alpha$. This is due to the process of convergence to the new steady state. For example, in Fig. 1, with an initial level of $\alpha=0.8$, the economy is in a steady state. With an increase in the level of RS to 0.9 , the old steady state does not hold any more. With higher RS, there will be higher level of capital and output in the economy in the new steady state capital and output. As in a standard growth model, when the initial steady state is below the optimal, there is a convergence process. Therefore, investment increases at a faster rate initially and overshoots. Since investment is connected to credit, credit also overshoots and, similarly, since deposits are connected to credits, deposits overshoot also. Since capital and labor are complements in the production, when investment shoots, labor also shoots to support the output. We can see this convergence process in the growth rate of output. The slope of the output in Fig. 1 is the growth rate of output. Initially the slope is very steep since the initial point is far from the new steady state, but as we get closer to the new steady state, convergence slows, slope becomes flatter and overshooting disappears.

Proposition 1. The higher the value of $\alpha$ the greater are the steadystate levels of per capita output, wages, credit, investment and capital, and the lower are the interest rates.

Simulations (not reported) also reveal that the smaller the level of $\alpha$ to start with, the greater are the changes in the steady-state values of output, consumption, capital, labor, investment, credit, deposit, profit, wage, interest rate and saving in response to a shock to $\alpha^{24}$

Proposition 2. The smaller the initial value of $\alpha$, the higher is the (transitory) growth rate.

\footnotetext{
21 Discount rate may vary across different characteristics of people, such as age, income groups and gender.

22 Nadiri and Prucha (1996) show that the depreciation rate for physical capital is 0.06 and for R\&D is 0.12 for the US manufacturing sector.

${ }^{23}$ Mankiw et al. (1992) show that $\beta=1 / 3$ for US.

24 According to the empirical investigation of Andres et al. (2004), growth dynamics of the OECD countries cannot only be explained by convergence due to the transitory dynamics; convergence in steady-state determinants play a great role for the observed reduction in per-capita incomes. Changes in RS should be considered as among those determinants; as the institutions literature suggests, transaction-cost reducing institutions such as RS are part of the production technology.
} 
Response to Alpha Shocks: Perfectly Competitive Banks
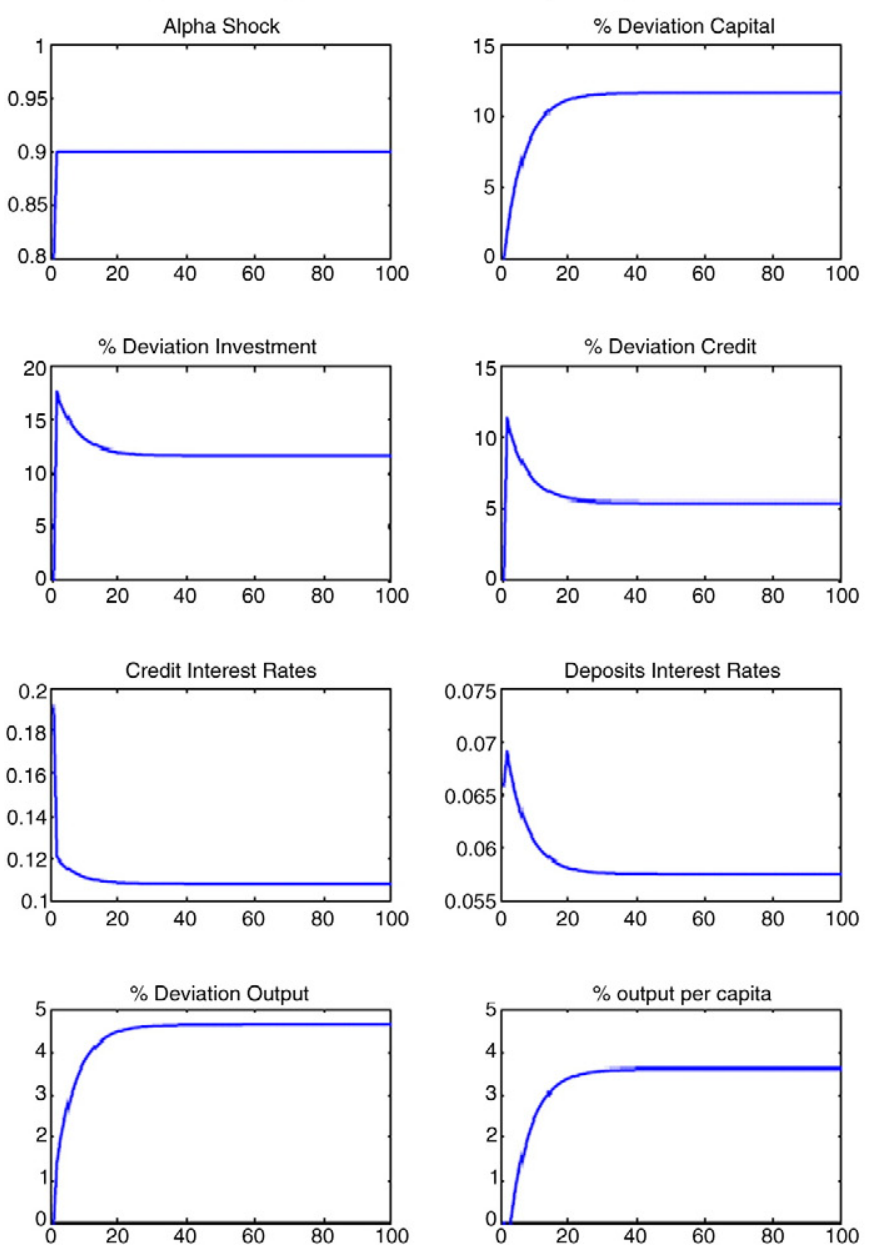
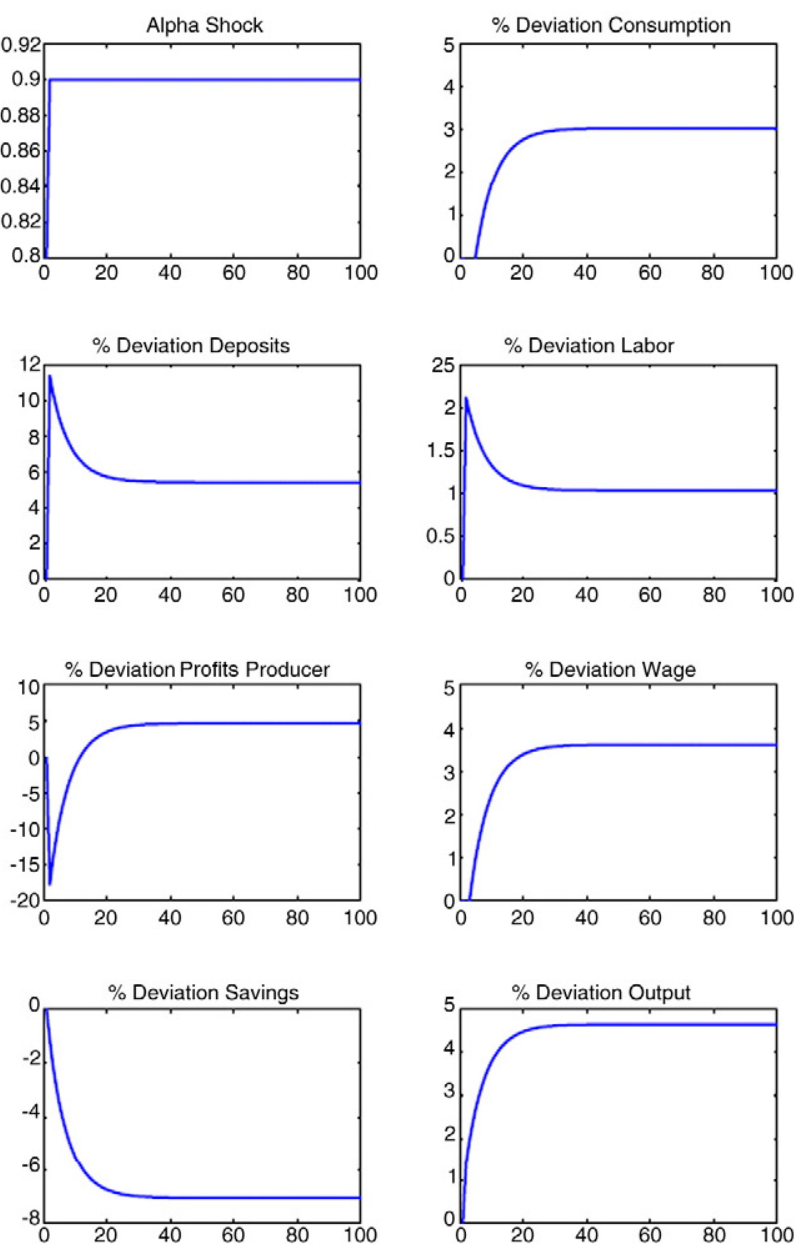

Fig. 1. Perfectly competitive banks; responses of model variables to a $(0.10)$ shock to $\alpha$.

\subsection{Bank as a monopoly}

As alternative to the above benchmark case, we now consider the case where the bank is a monopoly in the credit market and optimally chooses the lending rate of interest; the deposit rate is still assumed to be determined in competitive markets. In this case, credit rationing is possible, and the producer optimally chooses $N$ and credit demand, instead of $K$ :

$\sum_{t=0}^{\infty} \gamma^{t} \lambda_{t} \Pi_{t}^{\text {Firm }}=\sum_{t=0}^{\infty} \gamma^{t} \lambda_{t}\left\{A_{t} K_{t-1}^{\beta} N_{t}^{1-\beta}-w_{t} N_{t}-\sqrt{\alpha} C R_{t}\left(1+r_{t}\right)\right\}$

The last term in the brackets of Eq. (6') indicates the interest paid by the firm on a portion of credits. Maximizing Eq. $\left(6^{\prime}\right)$ subject to the constraints given by Eqs. (7) and (8) yields the following expressions (Eqs. (10') and (14)) for wage and credit demand, respectively:

$w_{t}=(1-\beta)\left[(1-\delta)\left(K_{t-1} / N_{t}\right)+\sqrt{\alpha}\left(C R_{t} / N_{t}\right]^{\beta}\right.$

$c r_{t}^{D}=C R_{t} / N_{t}=\left[\left(\frac{\beta}{1+r_{t}}\right)^{\frac{1}{1-\beta}}-(1-\delta)\left(K_{t-1} / N_{t}\right)\right](1 / \sqrt{\alpha})$

The monopolist bank maximizes its profits given by Eq. (11) with respect to $r_{t}$. Using Eq. (14), maximizing Eq. (11) subject to the constraint (12) yields the following expression for $r$ :

$$
\left[\left(\frac{\beta}{1+r_{t}}\right)^{\frac{1}{1-\beta}}-(1-\delta)\left(K_{t-1} / N_{t}\right)\right]=\left[\left(\frac{\beta}{1+r_{t}}\right)^{\frac{1}{1-\beta}} \frac{1}{(1-\beta)\left(1+r_{t}\right)}\right]\left[\left(1+r_{t}\right)-\frac{1+r_{t}^{D}}{\sqrt{\alpha}}\right]
$$

Eqs. (14) and (15) yield the following optimal solution for credit:

$c r_{t}=\frac{1}{\sqrt{\alpha}}\left[\left(\frac{\beta}{1+r_{t}}\right)^{\frac{1}{1-\beta}} \frac{1}{(1-\beta)\left(1+r_{t}\right)}\right]\left[\left(1+r_{t}\right)-\frac{1+r_{t}^{D}}{\sqrt{\alpha}}\right]$

Partial derivatives with respect to RS are found positive for $\mathrm{cr}$ (and hence for $k, y$ and $I)$ and $w$, and negative for $(1+r)$, which are the same results as in the case of perfectly competitive banks. To further analyze the impact of RS, we next look at the magnitude and direction of the effects of $\alpha$ on the simulated optimal trajectories of model variables over time, as reported below.

\subsubsection{Simulations}

Fig. 2 presents the simulation results of increasing $\alpha$ in the case of monopolist bank. When these results are compared with the case of a monopolist bank (see Fig. 2), we see that the effects of an increase in $\mathrm{RS}$ are higher in the competitive banking case. For example, a closer look at the figures shows that capital increases more than $10 \%$, labor increases more than $1 \%$ and output increases more than $4 \%$ in the 
Response to alpha Shock: Monopolist Bank
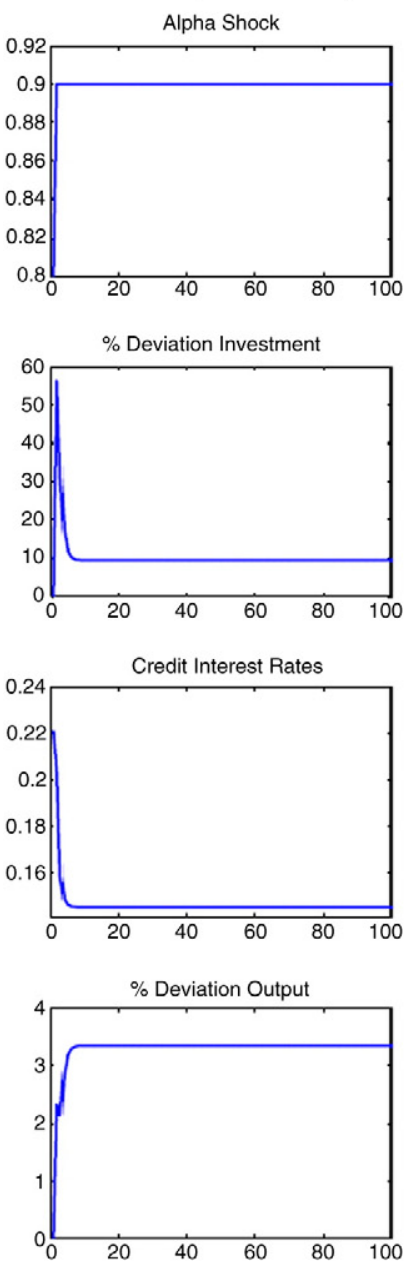
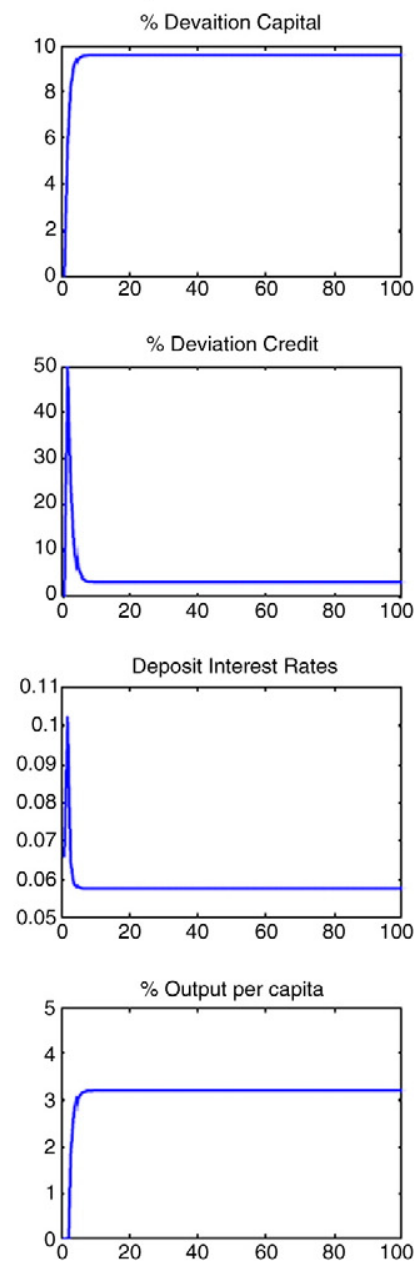

Fig. 2. Monopolist bank; responses of model variables to a (0.10) shock to $\alpha$.
Response to alpha Shock: Monopolist Bank
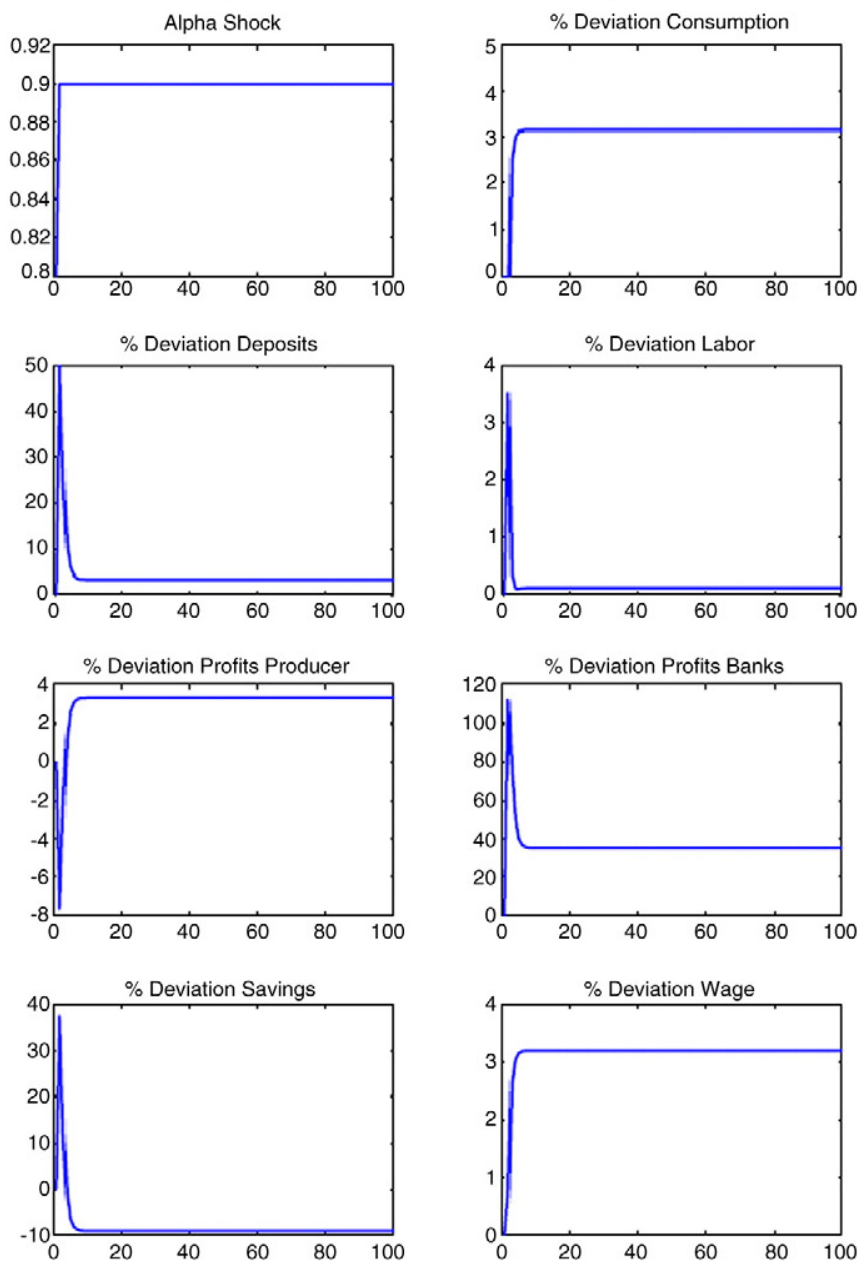

case of competitive banking. In contrast, capital increases less than $10 \%$, labor increase less than $1 \%$ and output increases less than $4 \%$ in the monopoly case. Therefore, observable welfare effects of an increase in RS are higher in competitive banking. On the other hand, immediate responses of many variables are higher in the case of monopolistic banks, indicating some sort of volatility. These results arise because monopoly is another source of inefficiency in the economy and a monopolist bank restricts the amount of credit in addition to moral hazard and asymmetric information problems. However, an improvement in the RS might decrease the monopoly power in the banking sector (not studied in the paper), and the results of monopoly would become closer to competitive case.

\section{Heterogeneous producers}

This section modifies the above model assuming that producers vary with a producer-specific moral hazard rate: $\left(1 / p_{i}\right)$, where $i(=1 \ldots n)$ is an index that indicates the producer type. $p_{i}$ is assumed to be distributed Beta in the $(0,1)$ interval, whose identifying parameters may take different values to proxy uniform, normal and skewed distributions. We specifically look at the cases of uniform, $\mathrm{F}$ and inverse-F distributions. ${ }^{25}$ To clarify, regardless of the value of $\alpha, p_{i}=1$ indicates that the type $i$ producer is willing to both invest and pay back to the bank $100 \%$ of the credit, and $p_{i}=0$ means that all the credit received by producer- $i$ is

${ }^{25}$ When the parameters of the Beta distribution are $(1,1)$, uniform distribution is obtained, when they are $(2,2)$, the distribution proxies the normal distribution. used for consumption and not returned to the bank, $100 \%$ of the credit turning into a non-performing loan.

Sections 3.1 and 3.2 show these modifications and their implications for the model's optimal solutions under the cases of both perfectly competitive and monopolist bank, respectively, facing heterogeneous agents. Section 3.3 investigates, for both perfectly competitive and monopolist bank types, the options of monitoring and not monitoring the producers.

\subsection{Heterogeneous agents with a perfectly competitive bank}

When there is a continuum of producer types, producer-i's problem is given by:

$\sum_{t=0}^{\infty} \gamma^{t} \lambda_{t} \Pi_{t, i}^{\text {Firm }}=\sum_{t=0}^{\infty} \gamma^{t} \lambda_{t}\left\{A_{t} K_{t-1}^{\beta} N_{t}^{1-\beta}-w_{t} N_{t}-p_{i}\left[K_{t}-(1-\delta) K_{t-1}\right]\left(1+r_{t}\right)\right\}\left(6^{\prime \prime}\right)$

The expression for investment (Eq. (8)) is also modified as:

$I_{t}=p_{i} \sqrt{\alpha} C R_{t}$

The bank's problem in case of heterogeneous producers is given by:

$\sum_{t=0}^{\infty} \gamma^{t} \lambda_{t} \Pi_{t}^{\text {Bank }}=\sum_{t=0}^{\infty} \gamma^{t} \lambda_{t}\left\{\left(1+r_{t}\right) p_{i} \sqrt{\alpha} C R_{t}-\left(1+r_{t-1}^{D}\right) D_{t-1}\right\}$ 
Solving Eq. (11') subject to Eq. (12) modifies the bank's first order condition as:

$\left(1+r_{t}\right)=\left(1 / \sqrt{\alpha} p_{i}\right)\left(1+r_{t-1}^{D}\right)$

The optimal solution of this problem implies that the increase in $p_{i}$ increases income, wages, credit and decreases the interest rate. ${ }^{26}$

\subsection{Heterogeneous agents with a monopolist bank}

A monopolist bank optimally chooses the interest rate, taking given the credit demand of the producer, who optimally chooses its credit and labor demand to maximize its profits given by Eq. $\left(6^{\prime \prime \prime}\right)$ :

$\sum_{t=0}^{\infty} \gamma^{t} \lambda_{t} \Pi_{t}^{\text {Firm }}=\sum_{t=0}^{\infty} \gamma^{t} \lambda_{t}\left\{A_{t} K_{t-1}^{\beta} N_{t}^{1-\beta}-w_{t} N_{t}-\sqrt{\alpha} p_{i} C R_{t}\left(1+r_{t}\right)\right\}$

which yields the modified first order conditions given by Eqs. (10") and $\left(14^{\prime}\right)$ :

$w_{t}=(1-\beta)\left[(1-\delta)\left(K_{t-1} / N_{t}\right)+\sqrt{\alpha} p_{i}\left(C R_{t} / N_{t}\right]^{\beta}\right.$

$C R_{t} / N_{t}=\left[\left(\frac{\beta}{1+r_{t}}\right)^{\frac{1}{1-\beta}}-(1-\delta)\left(K_{t-1} / N_{t}\right)\right]\left(1 / p_{i} \sqrt{\alpha}\right)$

Maximization of Eq. (11') by a monopolist bank yields the following revised first order condition for $\left(1+r_{t}\right)$ :

$\left[\left(\frac{\beta}{1+r_{t}}\right)^{\frac{1}{1-\beta}}-(1-\delta)\left(K_{t-1} / N_{t}\right)\right]=\left[\left(\frac{\beta}{1+r_{t}}\right)^{\frac{1}{1-\beta}} \frac{1}{(1-\beta)\left(1+r_{t}\right)}\right]\left[\left(1+r_{t}\right)-\frac{1+r_{t}^{D}}{p_{i} \sqrt{\alpha}}\right]\left(15^{\prime}\right)$

\subsection{Monitoring or no-monitoring}

In view of different potential moral hazard rates across the borrower types, banks face the alternatives of either monitoring the producers and assign them with individualized interest rates and credit; or not monitoring them and give each borrower a uniform interest rate and credit. In the case of no-monitoring, the expected producer type $E\left(p_{i}\right)$ is taken into consideration. The monitoring cost can be assumed to be a fraction of deposits and it increases with the extent of transaction cost, or decreases in $\alpha$. Optimum credit and interest rate decisions under monitoring and no-monitoring are considered in Sections 3.3.1 and 3.3.2, respectively.

\subsubsection{Monitoring (M)}

Banks' monitoring cost is expressed as a portion of its only resource: deposits, hence the bank's profit at time $t$ becomes:

$\Pi_{t}^{\text {Bank }}=\left(1+r_{t}\right) p_{i} \sqrt{\alpha} C R_{t}-\left(1+r_{t-1}^{D}+\phi(\alpha)\right) D_{t-1}$

where we assume $\phi(\alpha)=\sqrt{\log (1 / \alpha)} / 100 .^{27}$

Based on Eq. (11'), the following first order conditions for the credit and interest rates are obtained for perfectly competitive and monopolist banks, respectively ${ }^{28}$ :

$\left(1+r_{t}\right)=\left(1 / p_{i} \sqrt{\alpha}\right)\left(1+r_{t-1}^{D}+\phi(\alpha)\right)$

\footnotetext{
$\overline{26} \partial(1+r) / \partial p_{i}<0 ; \partial c r / \partial p_{i}>0 ; \partial y / \partial p_{i}>0 ; \partial w / \partial p_{i}>0$. These results hold under both monitoring and no-monitoring schemes.

27 This function is chosen for its smooth form and the reasonable values it provides for $0<\alpha<1$.

${ }^{28}$ For a competitive bank, the partial derivative of the interest rate with respect to the monitoring cost is: $[\partial(1+r) / \partial \phi(\alpha)]>0$.
}

$$
\left[\left(\frac{\beta}{1+r_{t}}\right)^{\frac{1}{1-\beta}}-(1-\delta)\left(K_{t-1} / N_{t}\right)\right]=\left[\left(\frac{\beta}{1+r_{t}}\right)^{\frac{1}{1-\beta}} \frac{1}{(1-\beta)\left(1+r_{t}\right)}\right]\left[\left(1+r_{t}\right)-\frac{1+r_{t}^{D}}{p_{i} \sqrt{\alpha}}\right]
$$

\subsubsection{No-monitoring (NM)}

In case banks do not monitor the firms, the interest rate for the expected producer type, $E\left(p_{i}\right)$, is uniformly charged to all firm types. ${ }^{29}$ Hence, the same amount of credit is extended to each producer type. Accordingly, the optimum rates of interest for perfectly competitive and monopolist banks are given, respectively, by:

$$
\begin{aligned}
& \left(1+r_{t}\right)=\left(1 / E\left(p_{i}\right) \sqrt{\alpha}\right)\left(1+r_{t-1}^{D}+\phi(\alpha)\right) \\
& {\left[\left(\frac{\beta}{1+r_{t}}\right)^{\frac{1}{1-\beta}}-(1-\delta)\left(K_{t-1} / N_{t}\right)\right]=\left[\left(\frac{\beta}{1+r_{t}}\right)^{\frac{1}{1-\beta}} \frac{1}{(1-\beta)\left(1+r_{t}\right)}\right]\left[\left(1+r_{t}\right)-\frac{1+r_{t}^{D}}{E\left(p_{i}\right) \sqrt{\alpha}}\right]}
\end{aligned}
$$

As in the case of monitoring as well, $p_{i}$ is observed to affect the main variables of the model in the same direction as $\alpha$ does. Simulations of credit demand and supply for producer types that are worse or better than $E\left(p_{i}\right)$ reveal that (see Fig. 3 ) there emerges excessive credit demand for the first type of (risky) borrowers, whereas there emerges excessive credit supply for the low-risk type. ${ }^{30}$ Since each producer invests and returns to the bank $p_{i} \sqrt{\alpha}$ percent of its credit, the worse is the distribution of producer types, the lower are the steady-state levels of investment and output; and the higher are the level of non-performing loans and, hence, the lower are bank profits and consumer utility. Fig. 3 shows that the banks' profit loss arising from higher than optimal interest rates offered to the better-than-average type producer is larger than the loss arising from offering lower than the optimal interest rates to the worse-thanaverage type producer. This implies higher cost of adverse selection in the case of better producer type than otherwise and hence, it appears that it pays off to banks to monitor producers when producer type gets better. Fig. 4 reports bank profit and $\alpha$ relationship for different $p_{i}$ distributions.

Proposition 3. Both bank profits and consumer utility increases in $\alpha$-regardless of the type of producers' distribution.

We additionally investigated the effects of income share of capital, which can be viewed as the level of development. Fig. 5 shows that an increase in $\alpha$ has a greater effect on bank profits the smaller the $\beta$, while the monitoring decision lowers profits only slightly (with or without monitoring, M). This indicates that the banking sector in less developed countries is likely to benefit more from reforming their regulatory and supervisory frameworks than the developed ones.

Proposition 4. The lower the value of $\beta$, the greater is the benefit from increasing $\alpha$.

As another indicator of development, simulations are also run for a higher rate of depreciation $(\delta=0.15)$. It is observed that the same amount of an increase in $\alpha$ benefits the country with higher depreciation rate more than the other. ${ }^{31}$

\section{Optimal regulation and monitoring}

Given Proposition 3, increasing RS ( $\alpha$ ) always appears to increase the welfare regardless of whether it is the social planner, who considers the combined benefit of the consumer with that of the bank,

\footnotetext{
29 To obtain tenable numbers for model variables, simulations reported below are based on the following range of pi values: $0.3 \leq p_{i} \leq 0.9$. Under no monitoring case the firm assumes a uniform distribution which leads $E\left(p_{i}\right)=0.6$.

30 The term excessive is in reference to the level of credit determined for the average producer type $\left[p_{i}=E\left(p_{i}\right)\right]$.

31 The results are available from the author upon request.
} 

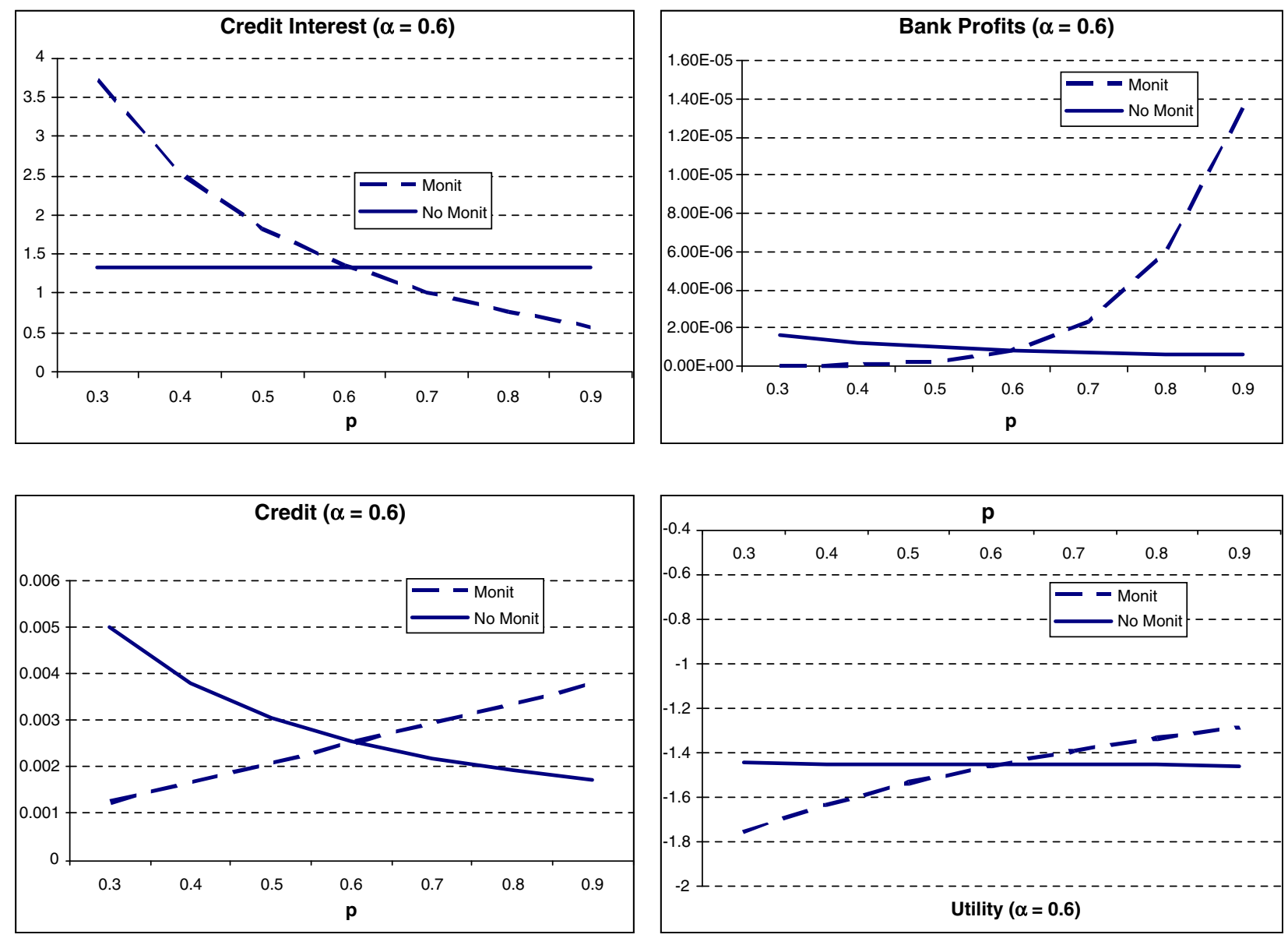

Fig. 3. Simulations of variables under monitoring versus no-monitoring.

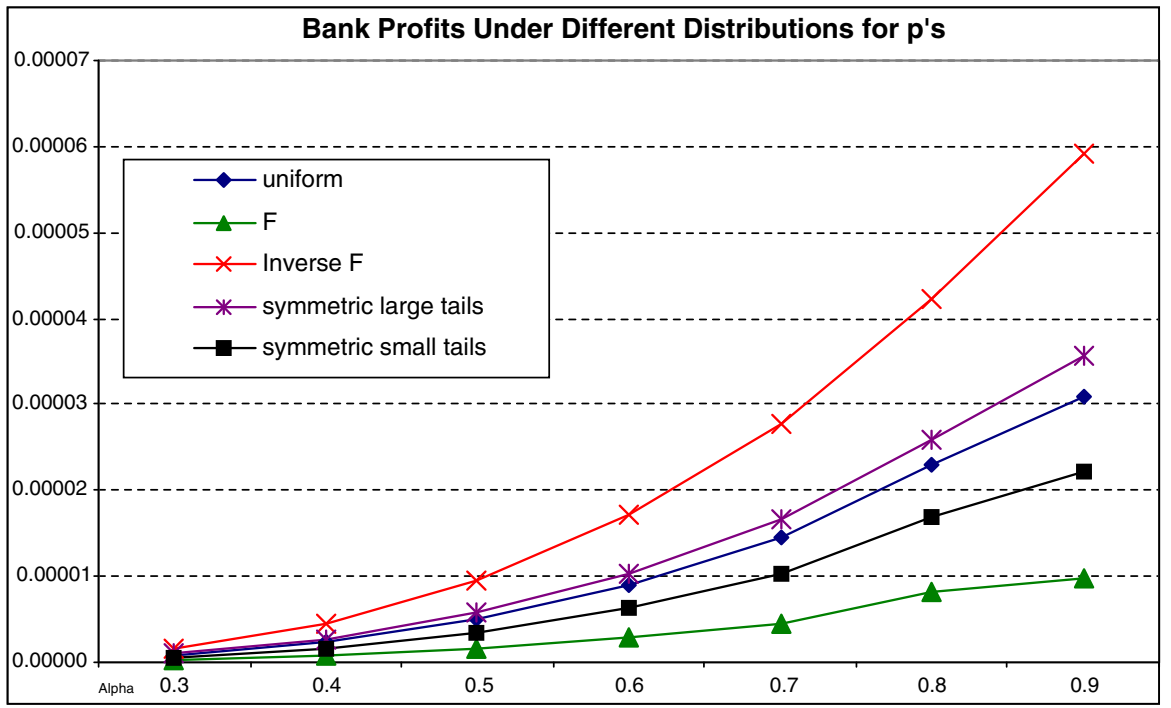

Fig. 4. Bank profits under monitoring for different $p_{i}$ distributions.

or the bank itself that optimizes $\alpha$. Notwithstanding the value of $\alpha$, banks still faces the decision to monitor or not to monitor. As in Neyapti and Ozgur (2007) who demonstrate that a strong central policy authority may relax the fiscal policy decision of decentralized governmental bodies, one can envision that the reaction of banks to a high $\alpha$ can be in the form of choosing not to monitor. Suppose that the bank chooses not to monitor and hence applies interest rates as if all producers are of the expected type $(p=0.6) .{ }^{32} \mathrm{Fig}$. 6 shows that this would lead to better profits than the monitoring scheme only if producers are distributed

\footnotetext{
32 See footnote 19
} 


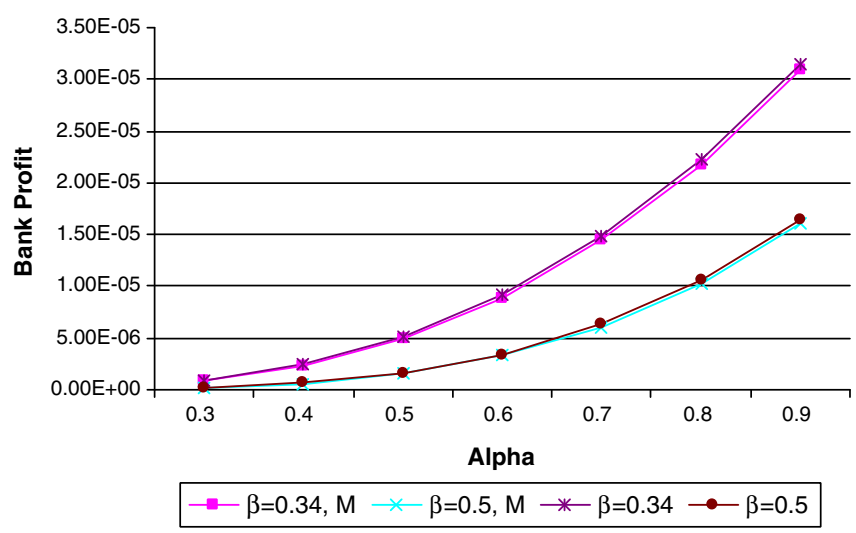

Fig. 5. Bank profits with or without M under different $\alpha$ s and $\beta$ s.

as F. In case the distribution type is inverse-F or uniform, however, NMscheme leads to lower bank profits than the M-scheme. Hence, if banks know the distribution of producers, the only case when they would optimally choose NM over M would be the case of F-distribution; in case the distribution of producers is known to be good or uniform, then it is optimal for banks to monitor.

To sum up, a high intensity of systemic regulation may lead banks to relax their monitoring effort that may reduce welfare under uncertainty regarding the producer type. A closer inspection of the simulation results (not reported) reveals that only in case producers are uniformly of a very
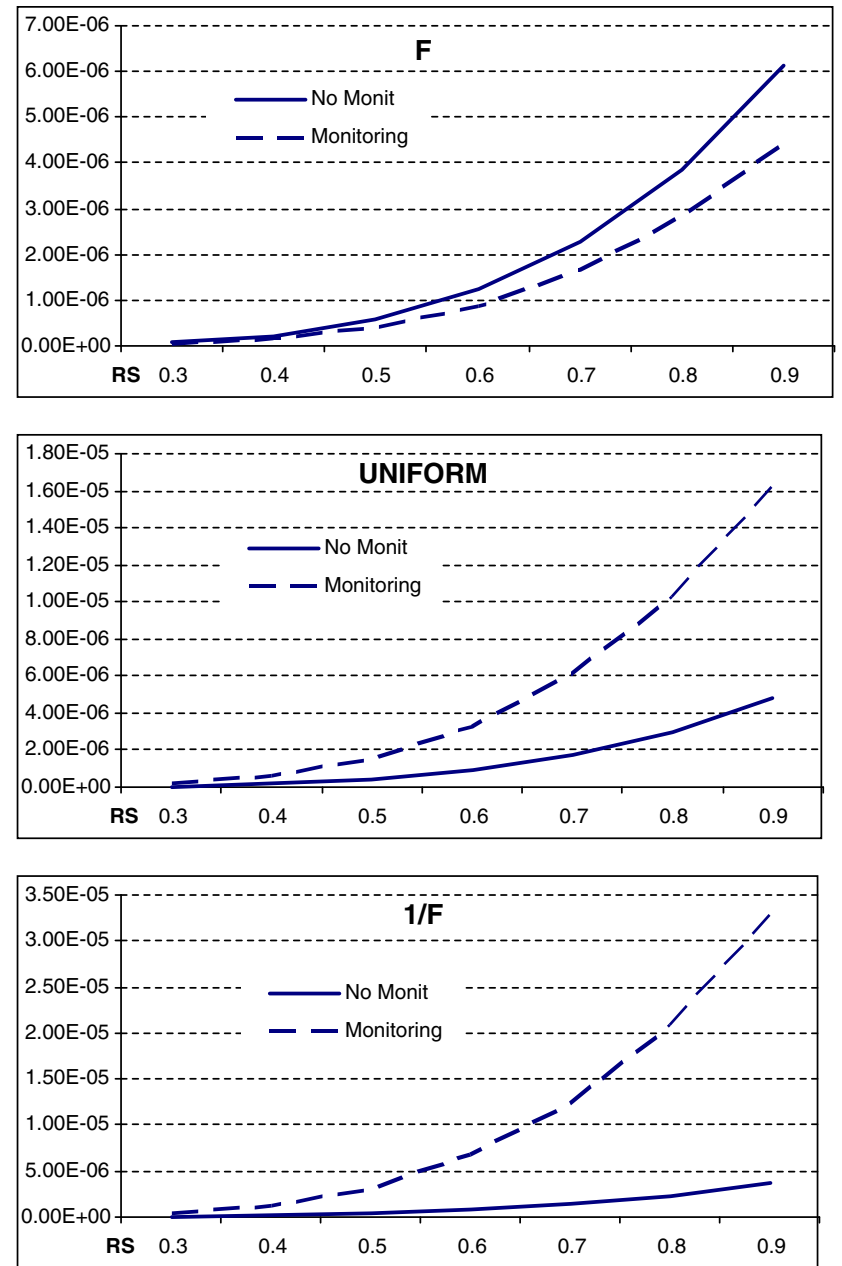

Fig. 6. Bank profits: monitoring versus no-monitoring for different $p_{i}$ distributions.
Monitoring Costs and Non-performing Loans as \% of Output

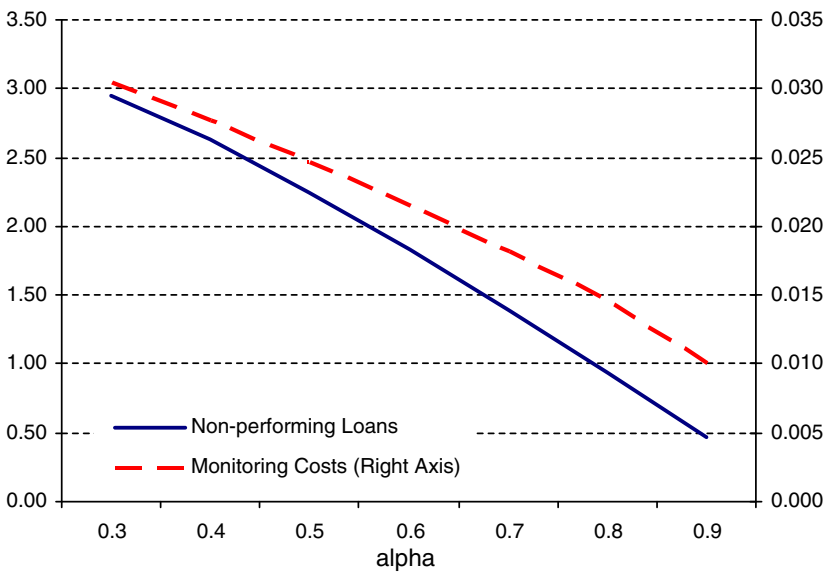

Fig. 7. Welfare gains of increasing $\alpha$.

low-risk type ( $\left.p_{i}>0.8\right)$ there is a range of $\alpha(\alpha>0.6)$ for which banks may prefer not to monitor.

Proposition 5. The better the distribution of producers, the more it pays to the banks to monitor than not to (though, in the extreme, higher $\alpha$ leads to no need to monitor, indicating a nonlinear effect of $\alpha$ ).

As a more general measure of welfare effects of $\alpha$, we plot the monitoring costs incurred by (monopolist) banks and non-performing loans (both measured as percentage of output) against $\alpha{ }^{33}$ Fig. 7 shows that both of these indicators decline with $\alpha$, indicating that increasing $\alpha$ is indeed an efficiency-enhancing institutional attribute. ${ }^{34}$

\section{Conclusion}

This paper provides an original model that formally shows the linkage between bank regulation and supervision (RS) and economic performance. The model is based on optimizing consumers, producers and banks, who live infinitely. Since RS stands for the formal institutional quality that affects the financial market operations, it is assumed to increase depositors' trust in the banking sector, and decrease the extent of moral hazard by the producers and hence the cost of monitoring facing the banks.

The solution of the model meets the basic predictions that RS positively affects the level of capital accumulation, income, deposits and wages, and negatively affects the interest rates. Simulations also show that increasing RS is associated with higher growth rates in transition to a higher steady state. Besides showing the positive welfare gains of increasing RS, the paper demonstrates that the positive impact of RS on between bank profits increases with the level of under-development, indicating that banks in developing countries have a higher incentive for reforming their banking laws than in developed countries. Simulations also reveal the interesting result that profit maximizing banks tend to prefer monitoring over no-monitoring the higher the RS and the better the distribution of producer types. This is because RS makes monitoring costs lower for banks.

\section{Appendix 1}

The underlying equations of the model with perfectly competitive bank

\footnotetext{
33 This is true under any type of distribution of $p_{i}$ 's since monitoring cost is assumed to be a fixed proportion of income for a given value of $\alpha$.

${ }^{34}$ A similar picture arises for non-performing loans under no monitoring.
} 
(Unknowns: $Y, N, K, C, S, I, D, w, r^{D}, r, C R, \Pi^{\text {Firm }}, \Pi^{\text {Bank }}$ )

1. $Y_{t}=A_{t} K_{t-1}^{\beta} N_{t}^{1-\beta}$

2. $C_{t}+S_{t} \leq w_{t} N_{t}+\alpha S_{t-1}\left(1+r_{t-1}^{D}\right)+(1-\alpha) S_{t-1}+(1-\sqrt{\alpha}) C R_{t}+\Pi_{t}^{\text {Firm }}+\Pi_{t}^{\text {Bank }}$

3. $U_{L}\left(C_{t}, L_{t}\right)=w_{t} U_{C}\left(C_{t}, L_{t}\right)$

4. $U_{C}\left(C_{t}, L_{t}\right)=\gamma U_{C}\left(C_{t+1}, L_{t+1}\right)\left[\alpha\left(1+r_{t}^{D}\right)+(1-\alpha)\right]$

5. $\alpha S_{t}=D_{t}$

6. $\Pi^{\text {Firm }}=\left[A_{t} K_{t-1}^{\beta} N_{t}^{1-\beta}-w_{t} N_{t}-\left[K_{t}-(1-\delta) K_{t-1}\right]\left(1+r_{t}\right)\right]$

7. $K_{t}=(1-\delta) K_{t-1}+I_{t}$

8. $I_{t}=\sqrt{\alpha} C R_{t}$

9. $\left(1+r_{t}\right) U_{C}\left(C_{t}, L_{t}\right)=\gamma U_{C}\left(C_{t+1}, L_{t+1}\right)\left[\beta\left(N_{t+1} / K_{t}\right)^{1-\beta}+\left(1+r_{t}\right.\right.$ $+1)(1-\delta)]$

10. $w_{t}=(1-\beta)\left(N_{t} / K_{t-1}\right)^{\beta}$

11. $\Pi^{\text {Bank }}=\left(1+r_{t}\right) \sqrt{\alpha} C R_{t}-\left(1+r_{t-1}^{D}\right) D_{t-1}$

12. $C R_{t} \leq D_{t-1}$

13. $\left(1+r_{t}\right)=(1 / \sqrt{\alpha})\left(1+r_{t-1}^{D}\right)$

\section{Appendix 2}

Comparative statics (homogenous producers and perfectly competitive banks).
1. $\frac{\partial\left(1+r_{t}\right)}{\partial \alpha}=-\frac{\left(1+r_{t-1}^{D}\right)}{2 \alpha^{3 / 2}}<0$.
2. $\frac{\partial w_{t}}{\partial \alpha}=\left(\frac{\beta(1-\beta) c r_{t}}{2 \sqrt{\alpha}}\right)\left[(1-\delta) \frac{K_{t-1}}{N_{t}}+\sqrt{\alpha} c r_{t}\right]^{\beta-1}>0$.
3. $\frac{\partial c r_{t}}{\partial \alpha}=\left[\left(\frac{\beta}{1+r_{t}}\right)^{\frac{1}{1-\beta}}\left(\frac{1}{(1-\beta)\left(1+r_{t}\right)}\right)\right]\left[\frac{\left(1+r_{t}\right)}{2}+\left(\frac{1+r_{t}^{D}}{\alpha \sqrt{\alpha}}\right)\right]\left(\frac{1}{\alpha}\right)$

\section{References}

Alen, F., Gale, D., 2007. Understanding Financial Crises. Oxford University Press, USA. Andres, J., Bosca, J.E., Domenech, R., 2004. Convergence in the OECD: transitional dynamics narrowing steady-state-differences? Economic Inquiry 42, 141-149.

Barth, J.R., Caprio, G., Levine, R., 2004. Bank regulation and supervision: what works best? Journal of Financial Intermediation 13, 205-248.

Beck, T., Levine, R., Loayza, N., 2000. Financial intermediation and growth: causality and causes. Journal of Monetary Economics 46, 31-77.

Bencivenga, V., Smith, B.D., 1991. Financial intermediation and endogenous growth. The Review of Economic Studies 58, 195-209.

Carlstrom, C., Fuerst, T.S., 2001. Monetary policy and asset prices with imperfect credit markets. Economic Review 04, 51-59.

Demirguc-Kunt, A., Huizinga, H., 2004. Market discipline and deposit insurance. Journal of Monetary Economics 512, 375-399.

Dincer, N., Neyapti, B., 2008. What determines the extent of bank regulation and supervision?: a mixed sample. Contemporary Economic Policy 26, 607-622.

Dincer, N., Neyapti, B., 2010. Macroeconomic Impact of Bank Regulation and Supervision: a cross-country investigation. Bilkent University Discussion Paper 10-05.

Goldsmith, Raymond W., 1969. Financial structure and development. Yale University Press, New Haven, CT.
Greenwood, J., Jovanovic, B., 1990. Financial development, growth, and the distribution of income. Journal of Political Economy 98, 1076-1107.

Hart, O., Moore, J., 1997. A theory of debt based on inalienability of human capital. Quarterly Journal of Economics 109, 841-879.

Holmstrom, B., Tirole, J., 1997. Financial intermediation, loanable funds, and the real sector. Quarterly Journal of Economics 112, 663-691.

Jensen, M.C., Meckling, W.H., 1976. Theory of the firm: managerial behavior, agency costs and ownership structure. Journal of Financial Economics 3, 305-360.

King, R.G., Levine, R., 1993. Finance and growth: Schumpeter might be right. Quarterly Journal of Economics 108, 717-737.

Levine, R., 1997. Financial development and economic growth: views and agenda. Journal of Economic Literature 35, 688-726.

Levine, R., 1998. The legal environment, banks, and long-run economic growth. Journal of Money, Credit, and Banking 30, 596-620.

Levine, R., 2003. More on finance and growth: more finance, more growth? Federal Reserve Bank of St. Louis Review 85, 31-46.

Lucas Jr., R.E., 1988. On the mechanics of economic development. Journal of Monetary Economics 22, 3-32.

Mankiw, G., Romer, D., Weil, D.N., 1992. A contribution to the empirics of economic growth. The Quarterly Journal of Economics 107, 407-437.

McKinnon, R.I., 1973. Money and capital in economic development. Brookings Institute, Washington, DC

Myers, S., Majluf, N.S., 1984. Corporate financing and investment decision when firms have information that investors do not have. Journal of Financial Economics 13, 187-221.

Nadiri, M.I., Prucha, I.R., 1996. Estimation of the depreciation rate of physical and R\&D capital in the US total manufacturing sector. Economic Inquiry 34, 43-56.

Neyapti, B., Dinçer, N., 2005. Measuring the quality of bank regulation and supervision and its macroeconomic effects-an application to transition economies. Economic Inquiry 43, 79-99.

Neyapti, B., Ozgur, S., 2007. The roles of fiscal and financial discipline on budgetary outcomes: the case of Europe. Contemporary Economic Policy 25, 146-155.

Rebelo, S., 1991. Long-run policy analysis and long-run growth. Journal of Political Economy 99, 500-512.

Repullo, R., Suarez, J., 1999. Entrepreneurial moral hazard and bank monitoring: a model of the credit channel. CEPR Discussion Paper No. 2060.

Rochet, J.C., 2004. Macroeconomic shocks and banking supervision. Journal of Financial Stability $1,93-110$

Romer, P.M., 1986. Increasing returns and long-run growth. Journal of Political Economy 94, 1002-1037.

Romer, P.M., 1990. Endogenous technological change. Journal of Political Economy 98, 1-102.

Schneider, M., Tornell, A., 2004. Balance sheet effects, bailout guarantees and financial crises. The Review of Economic Studies 71, 893-913.

Schumpeter, J.A., 1911. The theory of economic development. Harvard University Press, Cambridge, MA.

Shaw, Edward S., 1973. Financial deepening in economic development. Oxford University Press, New York.

Shehzad, C.T., de Haan, J., 2009. Financial Reform and Banking Crises. CESifo Working Paper Series 2870.

Stiglitz, J., Weiss, A., 1981. Credit rationing in markets with imperfect information. The American Economic Review 71, 393-410.

Tchana, F.T., 2007. The welfare cost of banking regulation. MPRA Paper 7588. University Library of Munich, Germany. 